\title{
Morphological features of Prosorhynchus crucibulum and $P$. aculeatus (Digenea: Bucephalidae), intestinal parasites of Conger conger (Pisces: Congridae), elucidated by scanning electron microscopy
}

\author{
Maria João Santos ${ }^{1}$ and David I. Gibson ${ }^{2}$ \\ ${ }^{1}$ Departamento de Zoologia e Antropologia, Faculdade de Ciências, Universidade do Porto, Praça Gomes Teixeira, 4099-002 \\ Porto, Portugal; \\ ${ }^{2}$ Parasitic Worms Division, Department of Zoology, The Natural History Museum, Cromwell Rd., London SW7 5BD, UK
}

Key words: Digenea, Bucephalidae, Prosorhynchus crucibulum, Prosorhynchus aculeatus, scanning electron microscopy, morphology, Conger conger

\begin{abstract}
The external morphology of two bucephalid digenean parasites of Conger conger (Linnaeus) (Congridae, Anguilliformes) caught northwest of the Iberian Peninsula, Prosorhynchus crucibulum (Rudolphi, 1819) Odhner, 1905 and P. aculeatus Odhner, 1905, were studied using scanning electron microscopy (SEM). SEM techniques elucidated new external morphological details, mainly relating to the tegument and protruding organs, such as, in P. crucibulum, a papilla-like structure associated with the pharynx and, in P. aculeatus, the cirrus. The tegument bears scale-like spines, which in both species are arranged quincuncially. The spines of $P$. crucibulum are wider than long and cover the major part of the body and rhynchus. However, no spines were found in either the central apical depression of the rhynchus or in the middle of the ventral indentation. Also, spines were rarely seen on the tegument around mouth, around the genital aperture or close to the excretory pore. P. aculeatus has spines of a different shape, as wide as they are long and with a rounded margin. They cover the whole body and almost the entire rhynchus, but none were found in the middle of the rhynchus or on its neck region.
\end{abstract}

Two species of Prosorhynchus Odhner, 1905, $P$. crucibulum (Rudolphi, 1819) Odhner, 1905 and $P$. aculeatus Odhner, 1905, are common parasites of the conger eel Conger conger (Linnaeus) (Congridae, Anguilliformes). They both infect this fish during their adult stage and tend to be host-specific (Matthews 1973), although apparently maturing in other congrids. Numerous authors have referred to their presence in the conger eel and, in many cases, a description of its morphology was provided (Odhner 1905, Nicoll 1910, Baylis and Jones 1933, Jones 1943, Bray 1973, Matthews 1973, Muñoz et al. 1989). Of the various morphological features, the scaly tegument is particularly important, as it is typical of bucephalids such as Prosorhynchus spp. It plays a major role in the process of attachment of the parasite to the host and in maintaining its position in the intestine (Matthews 1973). As a detailed study of this feature could be very useful in enabling a more accurate morphological characterisation of these worms, an investigation of the external features using scanning electron microscopy (SEM) was undertaken. The results of this study are presented below.

\section{MATERIALS AND METHODS}

Thirty-eight conger eels (Conger conger) were caught off the northwest coast of the Iberian Peninsula between Vigo, Spain and Vila Chã, Portugal during the months of May, 1998 and February, March, April, May, July and November, 1999. All parasites were collected from freshly killed fish.

The alimentary tract was removed, placed in a saline solution and kept in the refrigerator until examination. It was then separated into four portions, the stomach and the anterior, middle and posterior (rectal) regions of the intestine, prior to being opened using scissors. Bucephalid digeneans were collected and washed in saline solution, fixed with Berland's fluid and stored in $70 \%$ ethanol. Following Felgenhauer (1987), the specimens used for SEM were cleaned in order to remove excess mucus, dehydrated, coated with gold-palladium (ratio 4:1, thickness $20 \mathrm{~nm}$ ) and observed using a Hitachi SEM 2500 at an accelerating voltage of $15 \mathrm{kV}$.

Measurements of the tegumental spines were taken on SEM specimens. Measurements of the total length and width of the body were taken on worms mounted in glycerineethanol (1 part glycerine to 3 parts $70 \%$ ethanol) using light microscopy (LM) and are given as the mean \pm standard deviation followed with the range and number of measured specimens in parentheses. Additional observations of morphological details were also made using differential interference contrast (DIC) and LM on recently collected (May, 2000) live worms or those mounted in glycerine-ethanol; others were processed for histology using standard methods. Paraffin sections were stained with haematoxylin-eosin (H\&E) and resin sections were stained with toluidine blue.

Details of the prevalence and distribution along the alimentary tract were recorded for each parasite species (terminology follows Bush et al. 1997). 


\section{RESULTS}

Prosorhynchus crucibulum (Rudolphi, 1819) Odhner, 1905

Fig. 2

The infection prevalence was $71 \%$. The worms $(\mathrm{n}=$ $500)$ were mainly found in the anterior $(70.0 \%)$ and middle intestine (27.4\%) (Fig. 1).

Body foliaceous (Fig. 2 A, B), flattened and elongate, except distally where conical. Terminal rhynchus with slight apical depression and five indentations, two ventral (or subventral), one dorsal and two lateral (Fig. $2 \mathrm{C}$, D). Total body length 2,230 $\pm 230(1,880-2,600 ; \mathrm{n}$ $=20) \mu \mathrm{m}$, width $858 \pm 130(600-1,080 ; \mathrm{n}=20) \mu \mathrm{m}$.

Most parts of body armed with large, narrow scalelike spines; spines wider than long and arranged quincuncially. No spines present in two regions of rhynchus: central apical depression (Fig. 2 C) and middle of ventral indentation (Fig. 2 D). Spines on surface of remaining part of rhynchus small, multipointed, widely dispersed $(3.6 \times 2.3 \mu \mathrm{m})$ (Fig. $2 \mathrm{C}$ E). Size of spines decreases along body. Largest spines $(4.3 \times 3.3 \mu \mathrm{m})$ between base of rhynchus and level of mouth (Fig. 2 F). Towards posterior end of body, spines diminished in size, with multipointed and less exposed tips. Spines posterior to mouth $4.0 \times 2.6 \mu \mathrm{m}$ (Fig. $2 \mathrm{G}$ ); spines near genital pore smaller and more sparsely distributed. Few spines also present in tegument around mouth and around excretory pore at posterior extremity.

Mouth located in second quarter of body; pharynx may be protruded $50 \mu \mathrm{m}$ above general body surface. Single small, papilla-like structure present associated with anterior region of pharynx, located on anteroventral wall of pharynx just inside mouth, where it appears to overlie aperture of prepharyngeal pouch, apparently formed from set of longer pharyngeal muscle cells which are protruded to form digitiform, elastic structure, $38 \mu \mathrm{m}$ wide in live worms under pressure of a coverslip and 13-19 $\mu \mathrm{m}$ in fixed worms, 13-21 $\mu \mathrm{m}$ long in longitudinal sections; tip of papilla exposed (straight) or covered by tegument (folded); this structure was seen in SEM preparations (Fig. $2 \mathrm{H}, \mathrm{I}$ ), worms mounted in glycerine-ethanol and DIC observations of live worms (Fig. $2 \mathrm{~J}$ ) and sectioned material (Fig. $2 \mathrm{~K}, \mathrm{~L}$ ). In sagittal and frontal histological sections several glandcells were seen around prepharyngeal pouch. Exposed antero-ventral wall of pharynx prominent within mouth (Fig. $2 \mathrm{~K}$ ). In one sectioned specimen possible secretion was observed close to margin of mouth.

Deposition of voucher specimens: The Natural History Museum, London, BMNH Reg. No. 2000.5.24.11-12.

\section{Prosorhynchus aculeatus Odhner, 1905}

Fig. 3

The infection prevalence was $68 \%$. The worms $(\mathrm{n}=$ $2,036)$ found were mainly in the rectum $(96.0 \%)$ (Fig. $1)$.
Body also foliaceous (Fig. 3 A, B) but only about half size of $P$. crucibulum: total body length $1,027 \pm$ $160(880-1,320 ; \mathrm{n}=15) \mu \mathrm{m}$, greatest width $475 \pm 118$ (320-600; $\mathrm{n}=15) \mu \mathrm{m}$.

Rhynchus circular, quite different from $P$. crucibulum, covered with spines $(2.3 \times 2.3 \mu \mathrm{m})$ except for depressed central region and neck (Fig. 3 C, D). Spines disposed quincuncially (Fig. $3 \mathrm{C}$ ) throughout body, as wide as long and with exposed tips of spines apparently not pointed, decreasing in size towards excretory pore. Largest spines $(3.6 \times 3.6 \mu \mathrm{m})$ just posterior to rhynchus, with circular outline (Fig. 3 E). Smaller spines $(2.3 \times$ $2.3 \mu \mathrm{m})$ present anterior to mouth (Fig. $3 \mathrm{~F}$ ) and even smaller spines $(1.7 \times 1.7 \mu \mathrm{m})$, apparently multipointed, occurred posterior to mouth (Fig. $3 \mathrm{G}$ ).

In contrast to $P$. crucibulum, mouth not prominent, located at about junction between third and last quarters of body, and oriented towards posterior end of body (Fig. $3 \mathrm{~A}, \mathrm{H}$ ).

Genital aperture on ventral surface, close to posterior extremity; in one case protruded cirrus was very evident (Fig. 3 I).

Deposition of voucher specimens: The Natural History Museum, London, BMNH Reg. No. 2000.5.24.8-10.

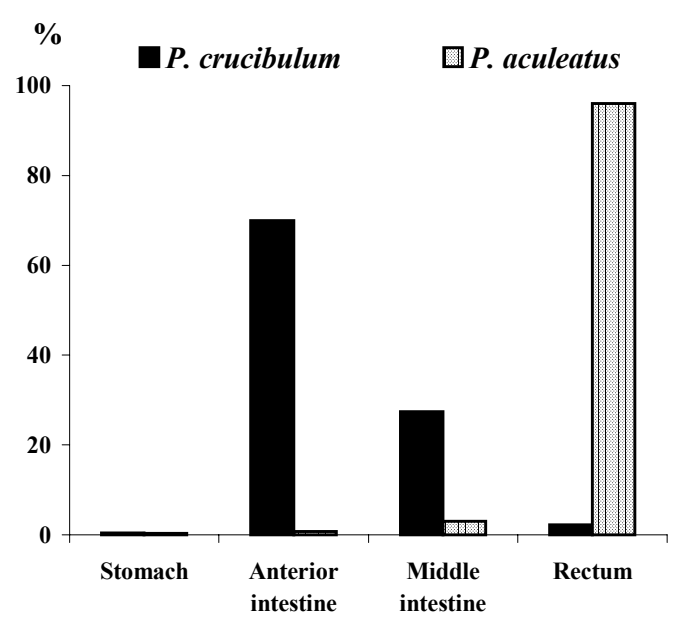

Fig. 1. Distribution of Prosorhynchus crucibulum and P. aculeatus in the gut of Conger conger.

\section{DISCUSSION}

Although Prosorhynchus crucibulum and P. aculeatus have been recorded in numerous works, only a few authors provide quantitative information on their occurrence. Nicoll (1910) referred to these species as being frequent in the intestine of the conger eel. For $P$. aculeatus this author also mentioned that "it occurs in moderate numbers". Muñoz et al. (1989) made the first references to prevalence and intensity values for these 


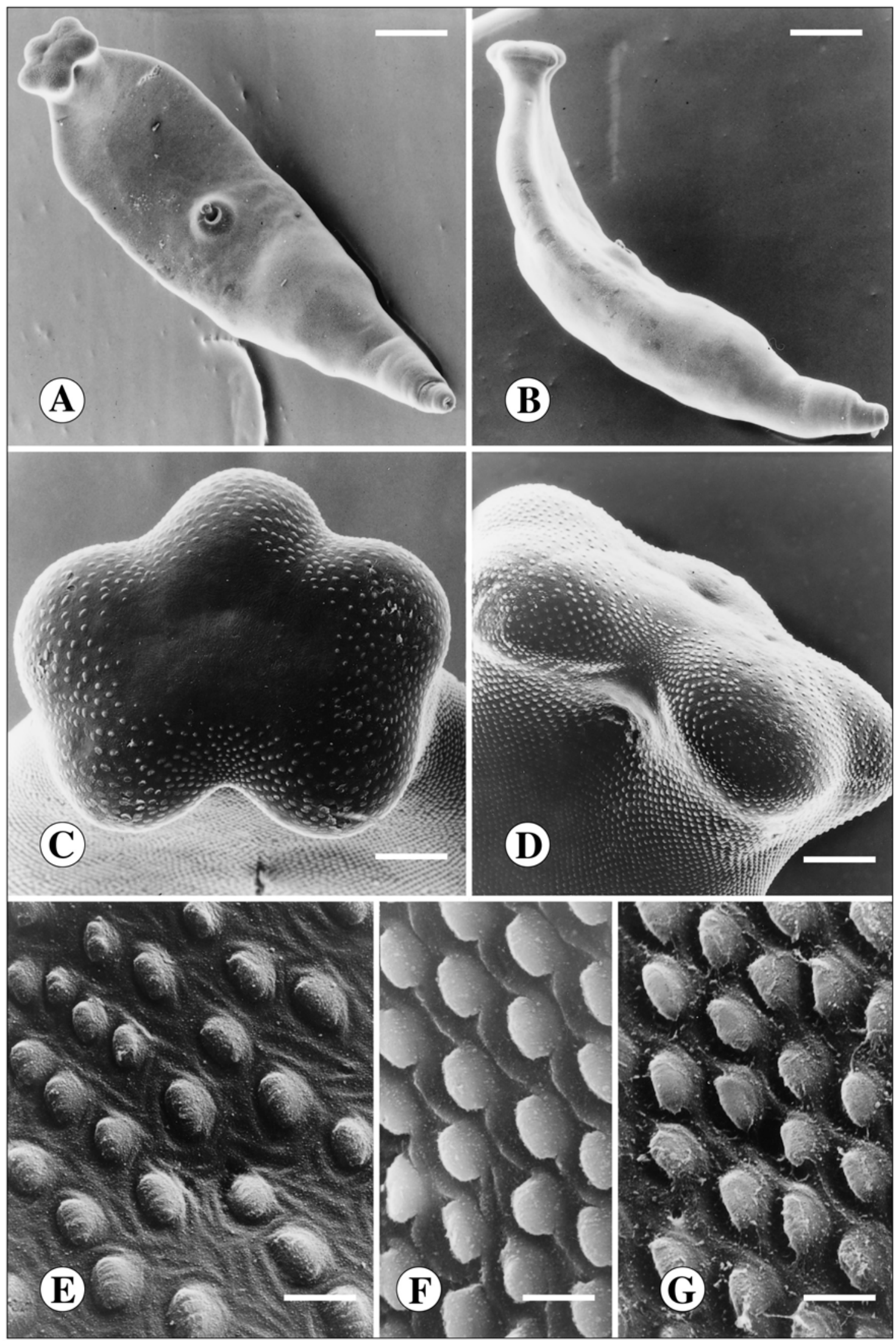


Santos, Gibson: Morphological features of species of Prosorhynchus
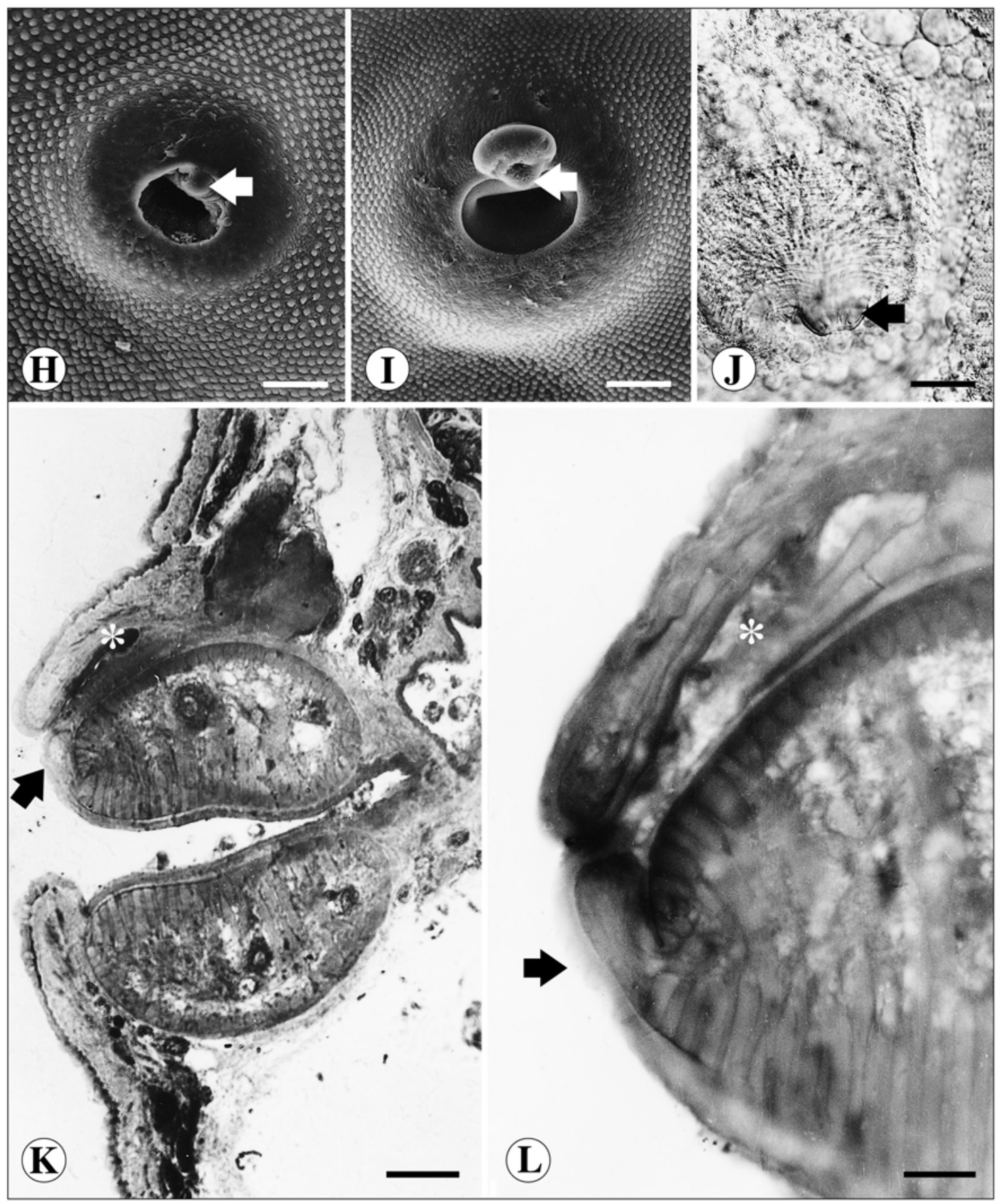

Fig. 2. Prosorhynchus crucibulum (Rudolphi, 1819) Odhner, 1905, scanning electron microscopy (A-I), differential interference contrast (J) and toluidine blue stained histological sections (K, L). A - ventral view; B - lateral view; $\mathbf{C}-$ en face view of the rhynchus; $\mathbf{D}$ - ventral view of the rhynchus; $\mathbf{E}$ - rhynchal spines; $\mathbf{F}$ - spines posterior to the rhynchus; $\mathbf{G}$ - spines posterior to the mouth; H-J - mouth with papilla (arrow); K, L - longitudinal section through pharynx with papilla (arrow) and prepharyngeal pouch (asterisk). Scale bars: A, B $=250 \mu \mathrm{m} ; \mathrm{C}=50 \mu \mathrm{m} ; \mathrm{D}=43 \mu \mathrm{m} ; \mathrm{E}-\mathrm{G}=5 \mu \mathrm{m} ; \mathrm{H}-\mathrm{J}=34 \mu \mathrm{m} ; \mathrm{K}=48 \mu \mathrm{m} ; \mathrm{L}=11 \mu \mathrm{m}$.

two parasite species in the conger eel, which were caught off Valencia (on the Mediterranean coast of Spain). Nevertheless, the figures presented by these authors, i.e. prevalence of $2.6 \%$ and $1.3 \%$ for $P$. crucibulum and $P$. aculeatus, respectively, are low in comparison with those reported here, i.e. $71 \%$ and $68 \%$, respectively.

Matthews (1973) described distinct locations for each of these species in the alimentary tract, a finding confirmed in the present work. Indeed, extremely high 


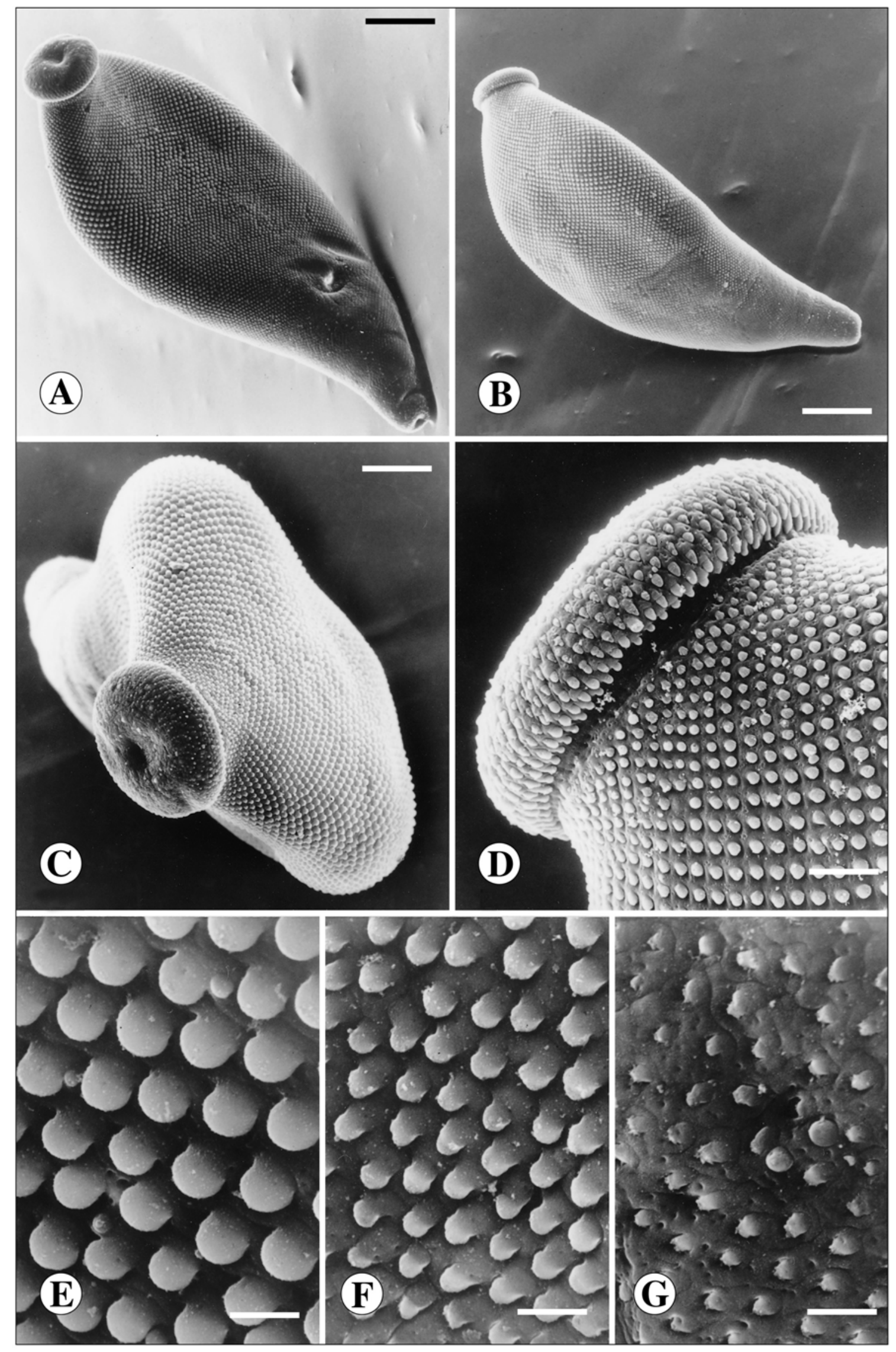




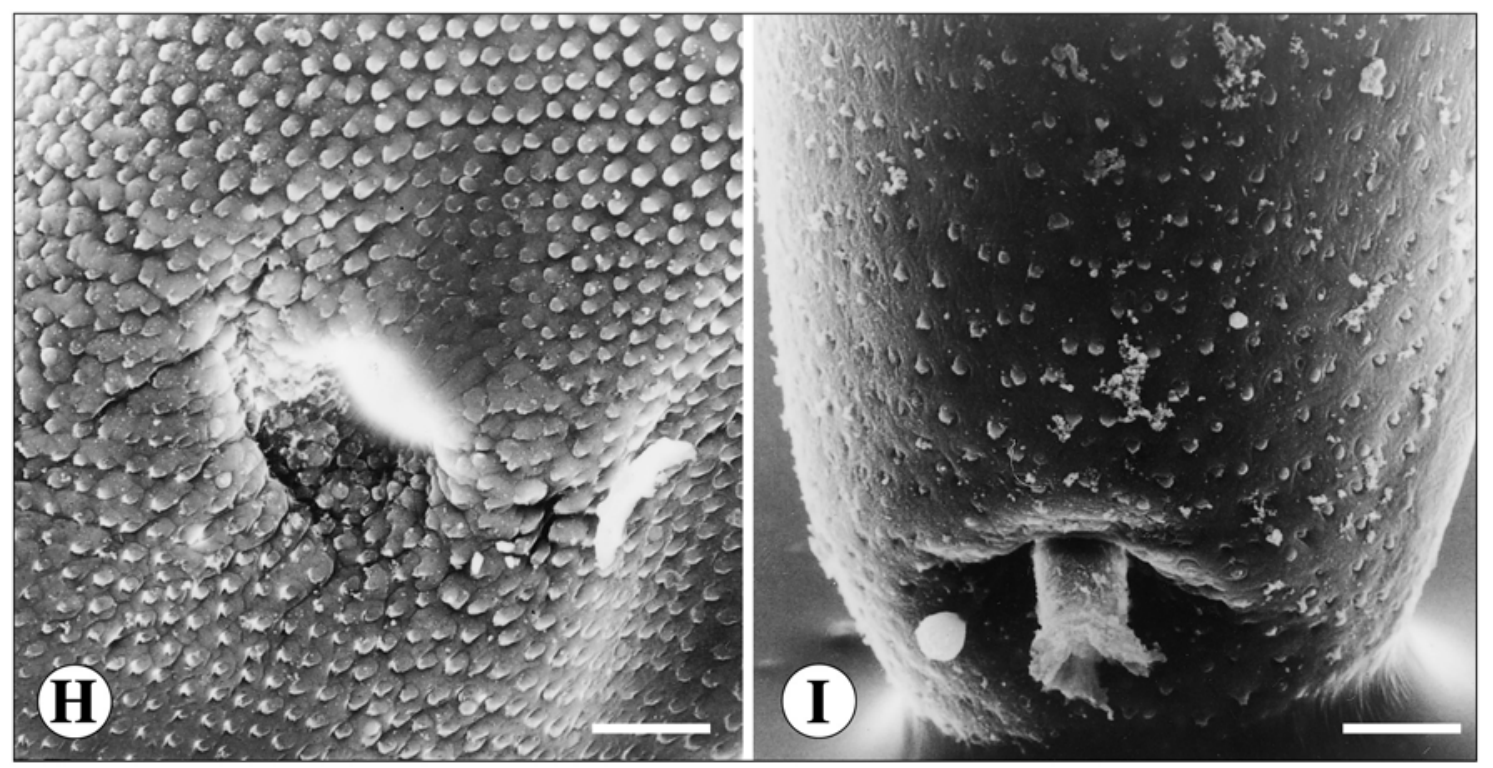

Fig. 3. Prosorhynchus aculeatus Odhner, 1905, scanning electron microscopy. A - ventral view; B - dorsal view; C - en face view of the worm; $\mathbf{D}$ - lateral view of the rhynchus; $\mathbf{E}$ - spines posterior to the rhynchus; $\mathbf{F}$ - spines anterior to the mouth; $\mathbf{G}-$ spines posterior to the mouth; $\mathbf{H}$ - mouth; $\mathbf{I}$ - posterior extremity of worm showing genital aperture and protruded cirrus. Scale bars: $\mathrm{A}=75 \mu \mathrm{m} ; \mathrm{B}=88 \mu \mathrm{m} ; \mathrm{C}=38 \mu \mathrm{m} ; \mathrm{D}, \mathrm{I}=14 \mu \mathrm{m} ; \mathrm{E}-\mathrm{G}=5 \mu \mathrm{m} ; \mathrm{H}=15 \mu \mathrm{m}$.

values of occurrence were detected for $P$. crucibulum in the anterior intestine and for $P$. aculeatus in the rectum. Both species share the intestine of the conger eel, although each tends to be restricted to a different niche. According to Matthews (1973), this pattern of distribution reflects the relative size of the worm's body and rhynchus in relation to size of the folds of the host's intestinal wall, which decrease in size down the intestine; hence $P$. crucibulum from the anterior intestine is much larger than $P$. aculeatus from the posterior intestine.

Several previous authors have referred to the presence of spines on the tegument of these two species of Prosorhynchus (see, for example, Nicoll 1910, Jones 1943, Bray 1973, Matthews 1973), but detailed information on their morphology is scarce. Relevant ultrastructural studies on bucephalids have been few and not especially informative (Bilqees 1976, Shalaby and Hassanine 1996, Tang et al. 1998), but indicate that spine-shape may be a useful taxonomic criterion at the specific level. Jones (1943) was the only author to give measurements for the spines of $P$. aculeatus, taken in specimens observed using light microscopy (LM). According to him, the spines on the anterior body and rhynchus were the largest $(14 \times 9 \mu \mathrm{m})$; in other parts of the body they were only $11 \times 8 \mu \mathrm{m}$. In our worms the spines are apparently shorter and exhibit a different shape, being wider than long; however, this can be explained by the different techniques used. In SEM observation only the exposed tip of the spines are observed. Hence, apparently smaller dimensions may have been obtained. The reported shape differences are also probably caused by the lower resolution of LM observations, as one can readily mistake the spines themselves for the sockets within the tegument in which they are implanted. Moreover, the rhynchal spine measurements of our material are clearly smaller $(2.3 \times$ $2.3 \mu \mathrm{m})$ than those from the anterior body $(3.6 \times 3.6$ $\mu \mathrm{m})$. Further down the body the spines become gradually shorter, reaching a minimum size of $1.7 \times 1.7$ $\mu \mathrm{m}$ just posterior to the mouth.

Another interesting feature of these two species of Prosorhynchus is that their spines are of a similar size, despite the significant difference in body dimensions. The largest spines of $P$. crucibulum measure $4.3 \times 3.3$ $\mu \mathrm{m}$, whereas those of $P$. aculeatus are $3.6 \times 3.6 \mu \mathrm{m}$. The relatively larger size of the spines of $P$. aculeatus may help the parasite's attachment to the host, compensating for the smaller rhynchus of this species.

Prosorhynchus crucibulum has no spines in the middle of the ventral indentation of the rhynchus. This may be related to features of the cercarial stage. In fact, Matthews (1973) showed that, at the cercarial stage, the apical region of the body forms a penetration organ, which is covered with spines except in its central region. As the metacercarial rhynchus has its origin in this penetration organ, it seems that its central region remains unspined through to the adult stage.

Perhaps the most interesting morphological feature elucidated by the SEM investigation relates to the region of the mouth of $P$. crucibulum. Matthews (1973) described the digestive system of this species as 
typically bucephalid, with a mid-ventral mouth, muscular pharynx and sac-like intestine. He also indicated the presence of a prepharynx and a prepharyngeal pouch with associated prepharyngeal glands. According to this author, the pharynx can be drawn down towards the mouth by the contraction of the muscles that attach it to the wall of the prepharynx and the body wall around the mouth. This mechanism can even enable the protrusion of the proximal end of the pharynx beyond the surface of the body, such that the prepharynx, but not the prepharyngeal pouch, is completely everted (Matthews indicated that the prepharyngeal pouch is squeezed during the process, possibly releasing the secretion of the prepharyngeal gland-cells). Although, based on our SEM observations, we cannot confirm this, the pharynx clearly causes a protrusion of the body-wall in the circum-oral region to a height of almost $50 \mu \mathrm{m}$ above the general body surface. However, the most obvious feature is a papilla-like structure located on the anterior pharyngeal wall, which was detected in all specimens studied using SEM and has not been described before. Consideration of the function of this structure is intriguing. It was seen in various degrees of protrusion and once apparently associated with a secretion from the prepharyngeal pouch (Fig. 2 I). This papilla overlies the aperture of the prepharyngeal pouch, where, we suggest, it may act as a cap which prevents secretions from the pouch being ingested by the mouth. We have also seen this structure in sectioned material (Fig. $2 \mathrm{~K}, \mathrm{~L}$ ) and in live worms (Fig. $2 \mathrm{~J}$ ). The same structure was not seen in $P$. aculeatus, for which Matthews reported that the prepharyngeal glands are only weakly developed. In $P$. crucibulum several gland-cells were seen around the prepharyngeal pouch, as described by Matthews (1973), in both sagittal and frontal histological sections, and would appear to be the source of the secretion.

Acknowledgements. The authors would like to acknowledge the financial support provided by Centro Inter-disciplinar de Investigaçao Marinha e Ambiental and the Bioresource LargeScale Facility Project under the European Commission's Training and Mobility of Researchers Programme. Alberto Correia kindly made available the alimentary tract of the conger eels. Dr. Aurélia Saraiva, Dr. Cristina Cruz and Dr. Sara Ferreira helped us with the collection of worms. The help of the staff of the Electron Microscopy \& Mineral Analysis Division of The Natural History Museum is also gratefully acknowledged. Dr. R.A. Bray kindly read and commented on the manuscript.

\section{REFERENCES}

BAYLIS H.A., JONES E.I. 1933: Some records of parasitic worms from marine fishes at Plymouth. J. Mar. Biol. Assoc. U.K. (n. s.) 18: 627-634.

BILQEES F.M. 1976: A comment on the relationship of Prosorhynchus thapari Manter, 1953 (Trematoda) from Plectorhynchus cinctus (T.S.) off the Karachi coast, with a note on its surface ultra-structure. Proc. Pak. Acad. Sci. 13: 29-33.

BRAY R.A. 1973: Some digenetic trematodes in fishes from the Bay of Biscay and nearby waters. Bull. Brit. Mus. (Nat. Hist.) (Zool.) 26: 151-183.

BUSH A.O., LAFFERTY K.D., LOTZ J.M., SHOSTAK A.W. 1997: Parasitology meets ecology on its own terms: Margolis et al. revisited. J. Parasitol. 83: 575-583.

FELGENHAUER B.E. 1987: Techniques for preparing crustaceans for scanning electron microscopy. J. Crustacean Biol. 7: 71-76.

JONES D.O. 1943: The anatomy of three digenetic trematodes, Skrjabiniella aculeatus (Odhner), Lecithochirium rufoviride (Rud.) and Sterrhurus fusiformis (Lühe) from Conger conger (Linn.). Parasitology 35: 40-57.
MATTHEWS R.A. 1973: The life-cycle of Prosorhynchus crucibulum (Rudolphi, 1819) Odhner, 1905, and a comparison of its cercaria with that of Prosorhynchus squamatus Odhner, 1905. Parasitology 66: 133-164.

MUÑOZ M.V., FERNÁNDEZ J.P., CARBONELL E., ORTS M.E. 1989: Contribución al estudio de algunos bucefálidos (Trematoda: Bucephalidae) parásitos de peces marinos de aguas ibéricas. Rev. Ibér. Parasitol. 49: 27-35.

NICOLL W. 1910: On the Entozoa of fishes from the Firth of Clyde. Parasitology 3: 322-359.

ODHNER T. 1905: Die Trematoden des arktischen Gebietes. Fauna Arct. 4: 289-372.

SHALABY I.M., HASSANINE R.M.E. 1996: On the rhynchus and body surface of three digenetic trematodes: Family: Bucephalidae Poche, 1907, from the Red Sea fishes based on scanning electron microscopy. J. Union Arab Biol., Cairo 5: 1-19.

TANG J.Y., WANG G.T., WANG W.J. 1998: [Scanning electron microscopic observation on five species of the family Bucephalidae.] Acta Hydrobiol. Sin. 22 (Suppl.): 170-176. (In Chinese.) 